\title{
Targetting Interleukins Involved in Glioblastoma - A New Pharmacological Approach
}

\author{
Aetsam Bin Masood, Mahmood Akhtar Kayani, Sajida Batoo* \\ Cancer Genetics and Epigenetics Laboratory, Department of Biosciences, COMSATS University, Islamabad, Pakistan \\ (aetsambinmasood@gmail.com; mkayani@comsats.edu.pk, sajida.batool@comsats.edu.pk) \\ *Correspondence: sajida.batool@comsats.edu.pk
}

\begin{abstract}
Brain tumor is unchecked growth of brain cells disrupting many of its important functions and, affecting molecular regulatory and signaling networks. Glioblastoma is one of the most deleterious tumors of human brain. Cytokines are secondary messenger molecules in many of the immunological and other biochemical reactions. With glioblastoma progression, various cytokines are secreted that either up-regulate or down-regulate many others with immunological function. Interleukins are a family of cytokines acting mainly as immuneregulatory proteins. They have been implicated in brain tumor initiation, progression and invasion. Due to their multiple and varied regulatory roles at every stage of tumor, they are now becoming an attractive target for study in glioblastoma. This mini review briefly summarizes the types and roles of major interleukins and their regulation and, effects in glioblastoma that have been studied so far. Immunotherapeutic aspects are particularly emphasized as the promising therapeutic targets to control brain tumors. Main types of

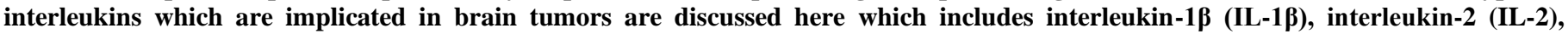
interleukin-4 (IL-4), interleukin-6 (IL-6), interleukin-8 (IL-8), interleukin-10 (IL-10), and interleukin-12 (IL-12). Glioblastoma is one of the most invasive tumor and still lack effective control measures clinically. Conventional treatments like chemotherapy and radiation therapy are not only ineffective in controlling the spread of glioblastoma, but also have damaging and unwanted side effects on healthy cells. Immunotherapy by blocking and/or increasing the action of certain interleukins has proven to be effective control measure in laboratory investigations. Future work extending these findings to clinical and human trials is expected to provide effective treatment measures.
\end{abstract}

Keywords: Glioblastoma, Interleukins, Cytokines, Immunotherapy, Pro-Inflammatory, Anti-Inflammatory

Received: October $12^{\text {th }}, 2020 /$ Accepted: December $10^{\text {th }}, 2020 /$ Online: December $20^{\text {th }}, 2020$

\section{INTRODUCTION}

Brain tumor is considered as intracranial neoplasm which can begin in the brain or central spinal cord, and involves uncontrolled division of neurons or glia. These tumors are secondary in nature in majority of the adults i.e. tumors are primarily located in other organs and then spread to the brain (Lapointe et al., 2018). Brain tumors are broadly classified as malignant or benign. Malignant are slow growing tumors and benign are localized. They are further categorized into astrocytomas and glioblastomas depending on the cell type of their origin. Other cell types where tumor originates are ependymomas, oligodendrogliomas and mixed gliomas. Maningiomas are benign and in the meninges of the brain. Pituitary gland tumors are also benign.
A cancer which is rare to start in the brain is known as central nervous system (CNS) lymphoma. Acoustic neuroma is associated with hearing nerve known as acoustic nerve. Germinomas and teratomas are the tumors of pineal gland. Medulloblastomas are more common in children than adults (Macmillan Cancer Support, 2017). Teratoid/Rhabdoid tumor (AT/RT) is a rare childhood tumor caused by inherited integrase interactor 1 (INI1) gene mutation acquired at specific time period during development (Janson et al., 2006). Many genetic and epigenetic aberrations have been identified in brain tumors. Genetic risk factors contributing to brain tumors have been mostly studied using mouse models. Epithelial growth factor receptor (EGFR) amplifications are the major well-studied genetic alterations in glioblastoma (GBM).

Ras signaling pathways have also been implicated in the progression of 
oncogenesis. Some studies suggest that Tensin homolog/protein kinase B (AKT), phosphatidylinositol 3-kinase (PI3Ks)/phosphatase and cyclin dependent kinase (CDK) pathways are altered too in GBM (Reilly et al., 2009; Ines et al., 2015).

Epigenetic alterations in brain tumors include hypermethylation of deoxyribonucleic acid (DNA) in promoter regions of cyclin dependent kinase inhibitor 2A (CDKN2A), serine protease 3 (PRSS3) and Ras association domain family protein 1A (RASSF1A) (Cui et al., 2006). Histone modifications notably $\mathrm{H} 3 \mathrm{~K} 9$ dimethylation increase, histone acetylation loss in $\mathrm{H} 2 \mathrm{~A}$, $\mathrm{H} 2 \mathrm{~B}, \mathrm{H} 3$, and $\mathrm{H} 4$ have also been reported. Increase in ubiquitination of $\mathrm{H} 2 \mathrm{~A}$ and $\mathrm{H} 2 \mathrm{~B}$ are also shown to be involved (Chen et al., 2006; Ke et al., 2008; Romani et al., 2018). GBMs are linked to transcriptional activation and demethylation of oncogenes known as MAGEA1 genes (Cadieux et al., 2006).

Overproduction of reactive oxygen species due to disruption of heavy metal homeostasis leads to DNA damage and formation of free radicals (Leonard et al., 2004). Perinatal risk factors, including high birth weight and familial risk factors are leading cause of tumors in childhood (Crump et al., 2015). Human polyomaviruses, which are DNA tumor viruses, are implicated in brain tumors too (White et al., 2005). Environmental factors also increase the risk of developing brain tumors. These factors include occupational exposures to electromagnetic fields, nitroso-containing compounds present in hair-styling products and to infectious agents during pregnancy and childhood (Connelly and Malkin, 2007). Heavy metals that can cause genetic and epigenetic changes are also linked to development and progression of brain tumors. Smoking is considered a risk factor too but the evidence of this causation has been conflicting so far (Vida et al., 2014).

\section{GLIOBLATOMA MULTIFORME}

Glioblastoma multiforme (GBM) is highly prevalent of all brain tumors. The term glioma is mainly used for primary brain tumors. Classification is performed on the basis of cells of the origin such as glioblastoma, astrocytoma, oligodendrogliomas and mixed gliomas. The malignant cells in GBM with infiltrating margins migrate towards the normal cells making it most invasive and aggressive glioma (Kleihues, 1997). GBM arises from glial cells or their precursors and is further categorized into four grades: grade- 4 being the most aggressive and also the most common in humans. People with GBM have a short life span and usually die within a year (Holland, 2000). An effective treatment for GBM is still lacking though various treatment approaches in the laboratories are under investigation.

\section{ROLE OF IMMUNE CELLS}

It is generally believed that cells with immune functions are unable to pass through the blood-brain barrier but several studies have shown that certain types are present in the perivascular meningeal space that include macrophages, $\mathrm{T}$ - lymphocytes (T-cells) and B-lymphocytes (B-cells). These are also found in the choroid plexus and are important in functioning of the brain as a whole (Tanabe and Yamashita, 2018). Under inflammatory conditions, microvascular endothelial cells produce soluble form of vascular cell adhesion molecule-1 (sVCAM-1). Integrin alpha-4 ( $\alpha-4)$ /beta-1 $(\beta-1)$ binding to sVCAM-1 directly impairs the blood-brain barrier through integrin $\alpha-4$ signalling pathway (Haarmann et al., 2015). Tumor associated macrophages (TAM) act in distinct microenvironments and promote cancer cells motility and angiogenesis in specific areas of invasion (Lewis and Pollard, 2006). Tumor necrosis factor alpha (TNF- $\alpha$ ) is a cytokine with important pro-inflammatory roles and, is released during various pathological processes (Feuerstein et al., 1994). Bonemarrow derived cells of host origin are tasked with class IMHC (major histocompatibility complex) restricted tumor antigens presentation (Huang et al., 1994). Microglia are important in inflammation derived diseases of central nervous system (CNS). The cytokines and growth factors secreted from these cells then invade brain neoplasms. Immune based treatment strategies of brain tumors have thus focused extensively on microglia and macrophages and cytokines secreted by them (Watters et al., 2005).

\section{CYTOKINES}

Cytokines are proteins produced by many cells of immune and non-immune origin and are involved in cellular communication and interactions. Cytokines can have effect on the cells from which they are being produced and/or can influence distant cells. Cytokines can be inflammatory or non- inflammatory in nature (Zhang and An, 2007). Cytokines affect nearly all processes in biological context. These include disease pathogenesis, specific antigenic response, non-specific response to infections, embryonic development, bone-marrow derived stem cell differentiation and allograft rejection. Cytokines are a large family of proteins having sub-families like chemokines, interleukins, interferons, mesenchymal growth factors, adipokines and tumor necrosis factors (Dinarello, 2007). One of the family of cytokines known as interleukins have been shown to have key roles in the pathogenesis of GBM.

\section{V.INTERLEUKINS}

Interleukins are mainly immune-regulatory proteins modulating wide range of cellular responses. They bind with their respective specific high-affinity receptors on their targets and the output depends on the ligands involved and signaling pathway activated (Commins et al., 2010). Interleukins have been reported to influence pathogenesis and malignancy of GBM. The amount and types of interleukins affects the expression of their targets either by up-regulation or downregulation. Given their role in inflammation, they are an attractive anti-inflammatory targets for therapeutic control (Yeung et al., 2013). One of their other important roles is to act 
as secondary-messenger molecules. A wide range of interleukins are present in GBM, and most notable are interleukin-1 $\beta$ (IL-1 $\beta$ ), interleukin-2 (IL-2), interleukin-4 (IL4), interleukin-6 (IL-6), interleukin-8 (IL-8), interleukin-10 (IL10), and interleukin-12 (IL-12). Here is a brief account of these interleukins in GBM together with their specific actions.

\section{INTERLEUKINS IN GBM}

\section{A. Interleukin-1 $\beta(I L-1 \beta)$}

IL-1 $\beta$ contributes to tissue damage by enhancing inflammatory mediators. It has been shown to be upregulated in GBM with positive correlation with carcinogenesis and tumor progression. Tumor progression can be halted by selectively inhibiting the IL-1 $\beta$ synthesis and activity given its pro-inflammatory roles. IL-6 and IL-8 are shown to have a direct relationship with IL$1 \beta$ expression while IL-4 is shown to have reverse association. Over expression of IL-1 $\beta$ enhances the formation of neurospheres and tumorigenicity of glioma cells (LN-229) (Albulescu et al., 2013; Wang et al., 2012).

Interleukin-1 family has been found to influence tumor spread to circulation and beyond in distant areas of the body. Gene expression programs in cancer-associated fibroblasts have been observed to be regulated by IL-1 $\beta$ treatment (Voronov et al., 2003; Dudas et al., 2011). IL-1 $\beta$ elevation caused down regulation of inwardly rectifying potassium (Kir) 4.1 channles in temporal cortex of epileptic rats (Zurolo et al., 2012). An increase in heat-shock protein CRYAB (Hsp B5) was also observed with elevated IL-1 $\beta$ in glioma implicating this in accelerated brain damage (Kore and Abraham, 2014). Given this pro-inflammatory and tumor promoting role of IL-1 $\beta$, future studies should be designed using selective inhibitors to block its activity as a promising treatment of GBM.

\section{B. Interlekin-2 (IL-2)}

Interleukin-2 is an anti-inflammatory cytokine of immense importance because it not only regulates inflammation but also helps to fight brain tumor. Different studies have shown IL-2 to be down regulated in glioblastomas. Lymphocytes within gliomas showed higher cytotoxic activity towards cancerous cells upon treatment with IL-2. IL-2 therapy was found to be effective in brain tumor repression and enhanced survival through intraoperative and postoperative injections (Seiichi et al., 1988; Danaila et al., 1993).

Autologous cancer vaccines containing IL-2 and IL-12 are also being administered in experimental settings to contain glioblastomas (Desaknai et al., 2001). Brain tumors are also targeted using genetically engineered allogeneic fibroblasts that produce IL-2 in animal gliomas and hence a ray of hope for humans as well (Lichtor et al., 2002). Transplanted glioblastomas tumor cells, which showed increased production of IL-2, exhibited enhanced tumor survival in murine models (Curran et al., 2011).

However IL- 2 is not exclusively anti-tumor in GBM and has been shown to alter Treg responses in GBM. It has been seen that these regulatory $\mathrm{T}$-cells lead to tumor progression through downregulation of IL-2 (Wainwright et al., 2013). IL-2 seems to have a paradoxical role in cancer causing both tumor progression and tumor-suppression. Further research work characterizing the IL-2 mediated processes is needed to fully comprehend its multifaceted role in GBM.

\section{Interleuki-4 (IL-4)}

Interleukin-4 is an anti-inflammatory cytokine of multiple roles produced by activated T-cells. It is shown to influence expression of adhesion molecules, activation of the JAK/STAT signalling, inhibition of cell proliferation, and angiogenesis, and infiltration of eosinophils into tumors (Kawakami et al., 2003; Volpert et al., 1998; Saleh et al., 1997). IL-4 injected with chimeric pseudomonas exotoxins in one study were found toxic to the tumor cells (Shimamura et al., 2006).

But IL-4 has also been found to facilitate tumor progression thus promoting a pro-tumor microenvironment. The pro and anti-tumor activities of IL-4 are dependent on the tissue-type and circumstances under which it is produced. Downregulation of IL-4 promotes development of $\mathrm{T}_{\mathrm{H} 2}$ responses which promote the invasion of eosinophils and switching to class $\operatorname{IgE}$ antibodies (Kazuya et al., 1996). Still, the therapeutic usefulness of IL-4 is being investigated despite its dual role in GBM warranting an extensive investigation into the mechanisms mediated.

\section{Interleukin-6 (IL-6)}

Interleukin- 6 is another important cytokine present in tumors of brain. Initially, IL-6 was considered a B-cell differentiation factor but now is known to perform numerous functions including neurogenesis i.e. generation of neurons and glial cells. It behaves in a neurotrohin like fashion and is classified under neuropoietins, a class of neural cytokines (Erta et al., 2012). IL-6 was found in glioblastoma in vivo and in vitro both (Meir et al., 1990). Its role in glioblastoma was previously unclear for several years but now its invasive roles are well studied. IL-6 administration was found to favor cell invasion in glioblastoma cell lines (U251 and T98G). It is also known to cause migration of vascular endothelium (Liu et al., 2010).

IL- 6 can be autocrine or paracrine for tumors. Its administration blocks effectively limiting its growth (Martinez and Berek., 1991). Elevated IL-6 in serum is observed at later stages of cancer. And so the blocking of IL-6 signalling is used as a therapeutic intervention using specific antibodies (Guo et al., 2012). If targeted signalling of interleukin-6 was performed, glioma stem-cells survival and growth of tumor can be suppressed (Wang et al., 2009).

\section{E. Interleukin-8 (IL-8)}

Interleukin-8 chemokine is considered pro-inflammatory. Various cell types can synthesize IL- 8 and one of its roles is to direct leukocytes to site of infection or injury. IL- 8 has been implicated in angiogenesis, activation and chemotaxis; and is up-regulated in oxygen deprived cells (Desbaillets et al., 1997). 
The serum levels of IL- 8 are elevated during cancer and recent studies have shown that tumor derived signaling of IL-8 enhances the migration of myeloid origin neutrophils and suppressor cells. IL-8 secreted by cells of tumor promotes epithelial to mesenchymal transition (EMT) thus increasing invasion metastasis (David et al., 2016).

MicroRNA-93 (miR-93), a type of RNA (ribonucleic acid), regulates expression of some genes involved in angiogenesis and gliomas including IL-8 (Fabbri et al., 2015). IL-8 produced by glioblastoma cells promoted permeability via $\mathrm{C}-\mathrm{X}-\mathrm{C}$ motif chemokine receptor 2 (CXCR2) in brain endothelial cells which is a receptor of IL-8 (Dwyer et al., 2012). Signal transducer and activator of transcription 3 (STAT3), is a transcription factor known for its tumor suppression, and its activity is mediated by IL-8 and carcinogenesis is enhanced when STAT3-IL-8 pathway was deregulated (Iglesia et al., 2008).

\section{F. Interlekin-10 (IL-10)}

Interleukin-10 role is anti-inflammatory and is synthesized by microglia, the innate immune cells of the central nervous system (Lobo-Silva et al., 2016). IL-10 can also be synthesized by cluster of differentiation $\left(\mathrm{CD}_{4}\right)$ expressing $\left(\mathrm{CD}_{4}{ }^{+}\right)$Tr1-cells (regulatory T-cells) and can show anti-tumor activity (Segal et al., 2005). Signalling through various Toll-like receptors (TLR) produces different cytokines, each having distinct functions. TLR3 signalling produced the highest rate of pro-inflammatory response following ligation of TLR4 (Jack et al., 2005). In rat models, activated astroglial and microglial cells produced IL10 and modulated glia-mediated inflammatory responses. IL-10 acts through autocrine and paracrine interactions with their high affinity receptors (Ledeboer et al., 2002).

Brain origin tumor necrosis factor in experimental mice was inhibited by systemic IL-10 administration (Di Santo et al., 1997). High grade tumors were found to have high expression of IL-10 mRNA (messenger ribonucleic acid) compared to tumors of low grade (Huettner et al., 1995). In mice, IL-10 has shown anti-tumor activity by prohibiting angiogenesis and down-regulating synthesis of vascular endothelial growth factor (VEGF), TNF-alpha, interleukin- $\beta$ and interleukin-6 (Huang et al., 1999). IL-10 is needed for T-cell functioning and it has immune stimulatory functions (Dennis et al., 2013). B7-H1 expression is up-regulated in circulating monocytes by modulation of IL-10 signaling, creating immune compromised phenotype (Bloch et al., 2013).

Table 1. A brief summary of the roles performed by Interleukins in Glioblastoma

\begin{tabular}{|c|c|c|}
\hline $\begin{array}{l}\text { INTERL- } \\
\text { EUKIN }\end{array}$ & ROLES & REFERENCES \\
\hline IL-1 $\beta$ & $\begin{array}{l}\text { Upregulated in brain cancer and } \\
\text { promotes tissue damage, invasion and } \\
\text { downregulation of kir4.1. }\end{array}$ & $\begin{array}{l}\text { (Albulescu et al., 2013; } \\
\text { Voronov et al., 2003; } \\
\text { Dudás } \text { et al., 2011; } \\
\text { Zurolo et al., 2012) }\end{array}$ \\
\hline IL-2 & $\begin{array}{l}\text { Downregulated in brain tumor and } \\
\text { modulates immune regulatory responses } \\
\text { that lead to cancer progression. }\end{array}$ & $\begin{array}{l}\text { (Seiichi } \text { et al., 1988; } \\
\text { Curran et al., 2011; } \\
\text { Wainwright } \text { et al., 2013) }\end{array}$ \\
\hline IL-4 & $\begin{array}{l}\text { An anti-inflammatory } \\
\text { promoting expression of adhesine } \\
\text { molecules, inhibition of cell } \\
\text { proliferation, induction of the } \\
\text { JAK/STAT signaling, inhibition of } \\
\text { angiogenesis and infiltration of } \\
\text { eosinophils into tumors. In some cases it } \\
\text { has also been shown to enhance tumor } \\
\text { spread thus having dual roles. } \\
\begin{array}{l}\text { Downregulated of IL-4 favors } \mathrm{T}_{\mathrm{H}} 2 \\
\text { responses. }\end{array}\end{array}$ & $\begin{array}{l}\text { (Kawakami } \text { et al., 2003; } \\
\text { Volpert } \text { et al., 1998; } \\
\text { Saleh } \text { et al., 1997; Li } \text { et } \\
\text { al., 2009; Kazuya } \text { et al., } \\
\text { 1996) }\end{array}$ \\
\hline IL-6 & $\begin{array}{l}\text { Upregulated in brain cancer and } \\
\text { promotes neurogenesis, and vascular } \\
\text { endothelial migration. Its administration } \\
\text { in tumors reduces cancer progression. }\end{array}$ & $\begin{array}{l}\text { (Erta } \text { et al., 2012; Liu } \text { et } \\
\text { al., 2010; Martinez and } \\
\text { Berek., 1991; Guo } \text { et al., } \\
\text { 2012) }\end{array}$ \\
\hline Il-8 & $\begin{array}{l}\text { A pro-inflammatory chemokine which } \\
\text { recruits lymphocytes and promotes } \\
\text { EMT thus favoring cancer progression. }\end{array}$ & $\begin{array}{l}\text { (David et al., 2016; } \\
\text { Fabbri et al., 2015) }\end{array}$ \\
\hline Il-10 & $\begin{array}{l}\text { An anti-inflammatory cytokine and } \\
\text { inhibits angiogenesis, endothelial } \\
\text { growth factor (VEGF) synthesis, TNF- } \\
\text { alpha, IL- } \beta \text { and IL- } 6 \text {. }\end{array}$ & $\begin{array}{l}\text { (Lobo-Silva et al., 2016; } \\
\text { Ledeboer et al., 2002; } \\
\text { Huang } \text { et al., 1999) }\end{array}$ \\
\hline Il-12 & $\begin{array}{l}\text { A link between innate and adaptive } \\
\text { immunity by promoting } \mathrm{T}_{\mathrm{H}} 1 \text { responses } \\
\text { and killing of tumor cells by cytotoxic } \mathrm{T} \text { - } \\
\text { cells and natural killer cells. }\end{array}$ & $\begin{array}{l}\text { (Tugues, et al., 2015; } \\
\text { Vom Berg } \text { et al., 2013; } \\
\text { Rutledge } \text { et al., 2013; } \\
\text { Hirohata, 1999) }\end{array}$ \\
\hline
\end{tabular}

\section{G. Interleukin-12 (IL-12)}

IL-12 has emerged as an attractive candidate in cancer treatment as of late. It exerts its anti-tumor activities through its pleotropic effects on immune cells. Adaptive and innate immune pathways are linked by IL-12 (Tugues, et al., 2015). IL-12 activates $T_{\mathrm{H} 1}$ responses which favors anti-tumor effect through natural killer cells and cytotoxic T-cells. IL-12 also stimulates the induction of co-stimulaory CD40 (Hirohata, 1999). Intra-tumoral IL-12 administration together with coinhibitory cytotoxic T-lymphocyte associated protein-4 (CTLA4) receptor inhibition results in death of tumor cells (Vom Berg et al., 2013). Tumor infiltrating lymphocytes (TILs) have also shown to have prognostic roles in GBM and their production can be stimulated by IL-12 in vitro (Weiss et al., 2007; Rutledge et al., 2013).

IL-12 inhibited growth of implanted glioblastomas in murine models thus increasing their survival in experimental models. In rat models, intracranial administration of recombinant adeno-associated virus encoding IL-12 (rAAV2/IL12) resulted in more activated microglia infiltration. The size of tumor was small in mice injected with rAAV2/IL-12 in contrast to nontreated controls (Chiu et al., 2012). The role of all the aforementioned interleukins has been summarized in Table 1. 


\section{CONCLUSION}

Interleukins are very important due to their pro-inflammatory and anti-inflammatory roles. Among the anti-inflammatory interleukins, IL-2, IL-4, IL-6, IL-10 and IL-12 can be used for the treatment of GBM. Likewise, IL-8 can be a good proinflammatory Interleukin to target. GBM is still one of the most invasive and therapy evading tumors. These interleukins have been investigated for their role in GBM and are effective targets for the control of GBM spread and its treatment.

\section{FUTURE PROSPECTS}

Immunotherapy for cancer treatment is a promising new approach which makes use of body's own immune system to get rid of malignant population. Blocking antibodies to stop cells from communicating or getting activated has been already been shown effective in slowing cancer progression and invasion. This is a targeted and effective approach to control cancer spread than traditional non-specific treatments like chemotherapy and radiotherapy which had their own associated cell damaging impacts. Anti-inflammatory cytokines should also be used to serve the purpose. These pro-inflammatory and anti-inflammatory cytokines could similarly be another effective target to control the spread of cancer.

\section{ACKNOWLEDGMENTS}

The authors are thankful to Dr. Nazneen Bangash for her valuable and critical input in writing this manuscript. The authors are also thankful to the Junaid Zaidi Library, COMSATS University Islamabad for allowing us to use their digital and print resources for literature search.

\section{CONFLICT OF INTEREST}

The authors have no conflict of interest to declare.

\section{FUNDING}

The work presented here did not receive a specific grant from any funding body.

\section{REFERENCES}

Albulescu, R., Elena, C., Ionela, D.P., Simona, M., Laura, G.N., Daniel, P., Mihaela, T., Cristiana, P. (2013). Cytokine Patterns in Brain Tumour Progression. Mediators of Inflammation, 2013, 7

Bloch, O., Courtney, A. C., Rajwant, K., Michael, S., Martin, J.R., Andrew, T.P. (2013). Gliomas promote immunosuppression through induction of B7-H1 expression in tumor-associated macrophages. Clinical Cancer Research, 19(12), 3165-3175.

Cadieux, B., Ching, T.T., VandenBerg, S.R., Costello, J.F. (2006). Genomewide hypomethylation in human glioblastomas associated with specific copy number alteration, methylenetetrahydrofolate reductase allele status, and increased proliferation. Cancer Research, 66(17), 8469-8476.

Chen, H., Qingdong, Ke., Thomas, K., Yan, Y., Max, C. (2006). Nickel ions increase histone $\mathrm{H} 3$ lysine 9 dimethylation and induce transgene silencing. Molecular Cell Biology, 26(10), 3728-3737.

Chiu, T.L., Wang, M.J., Su, C.C. (2012). The treatment of glioblastoma multiforme through activation of microglia and TRAIL induced by rAAV2-mediated IL-12 in a syngeneic rat model. Journal of Biomedical Science, 19(1), 45.
Commins, S.P., Borish, L., Steinke, J.W. (2010). Immunologic messenger molecules: cytokines, interferons, and chemokines. The Journal of Allergy and Clinical Immunology, 125 (2 Suppl 2), S53-S72.

Connelly, J.M., Malkin, M.G. (2007). Environmental risk factors for brain tumors. Current Neurology and Neuroscience Reports, 7(3), 208-214.

Crump, C., Sundquist, J., Sieh, W., Winkleby, M.A., Sundquist, K. (2015). Perinatal and familial risk factors for brain tumors in childhood through young adulthood. Cancer Research, 75(3), 576-583.

Curran, C.S., Michael, D.E., Paul, J.B. (2011). GM-CSF Production by Glioblastoma Cells Has a Functional Role in Eosinophil Survival, Activation, and Growth Factor Production for Enhanced Tumor Cell Proliferation. The Journal of Immunology, 187(3), 1254-1263.

Cui, X., Toshifumi W., Yoshio S., Katsuyoshi H., Seishiro H. (2006). Chronic oral exposure to inorganic arsenate interferes with methylation status of p16INK4a and RASSF1A and induces lung cancer in A/J mice. Toxicol Sci, 91(2), 372-381.

Danaila, L., Ghyka, G., Ursaciuc, C. (1993). Interleukin-2 (IL-2) in the treatment of malignant brain tumors (glioblastomas). Romanian Journal of Neurology and Psychiatry, 31(3-4), 195-206.

David, J.M., Charli, D., Duane, H.H., Claudia, P. (2016). The IL-8/IL-8 Axis: A double agent in Tumor Immune Resistance. Vaccines (Basel) 4(3),22.

Dennis, K.L., Nichole, R.B., Fotini, G., Khashayarsha, K. (2013). Current status of interleukin-10 and regulatory T-cells in cancer. Current Opinions in Oncology, 25(6), 637-645.

Desbaillets, I., Diserens, A.C., Tribolet, N. de., Hamou, M.F., Meir, E.G.V. (1997). Upregulation of Interleukin 8 by Oxygen-deprived Cells in Glioblastoma Suggests a Role in Leukocyte Activation, Chemotaxis, and Angiogenesis. The Journal of Experimental Medicine, 186(8), 12011212.

Desaknai, S., Katalin, L., Egon, J.H., Hirofumi, H., Geza, S. (2001). Brain tumor treatment with IL-2 and IL-12 producing autologous cancer cell vaccines. Advances in Experimental Medicine and Biology, 495, 369-372.

Di Santo, Adami M., Bertorelli R., Ghezzi P. (1997). Systemic interleukin 10 administration inhibits brain tumor necrosis factor production in mice. Eur J Pharmacol, 336(2-3), 197-202.

Dinarello, C.A. (2007). Historical Review of Cytokines. European Journal of Immunology, 37(Suppl 1), S34-S45.

Dwyer, J., Hebda, J.K., Le Guelte, A., Galan-Moya, E.M., Smith, S.S., Azzi, S., Gavard, J. (2012). Glioblastoma Cell-Secreted Interleukin-8 Induces Brain Endothelial Cell Permeability via CXCR2. PLoSONE, 7(9), e45562.

Dudas, J., Alexandra, F., Mario, B., Volker, S., Ilona, K., Georg, M.S., Herbert, R. (2011). Tumor-produced, active Interleukin-1 $\beta$ regulates gene expression in carcinoma-associated fibroblasts. Experimental Cell Research, 317(15), 2222-2229.

Erta, M., Quintana, A., Hidalgo, J. (2012). Interleukin-6, a Major Cytokine in the Central Nervous System. International Journal of Biological Sciences, 8(9), 1254-1266.

Fabbri, E., Eleonora, B., Giulia, M., Claudio, G., Albino, E., Cinzia, C., Susanna, K., Valentino, B., Lisa P., Nicoletta, B., Alessia, F., Monica, B., Giuseppe, M., Marco, C., Giulio, C., Roberto, G. (2015). Regulation of IL-8 gene expression in gliomas by microRNA miR-93. BMC Cancer, $15(1), 661$.

Feuerstein, G.Z., Liu, T., Barone, F.C. (1994). Cytokines, inflammation, and brain injury: role of tumor necrosis factor-alpha. Cerebrovascular and Brain Metabolism Reviews, 6(4), 341-360.

Guo, Y., Feng, X., TianJian, L., Zhenfeng, D., Zhan, Z. (2012). Interleukin-6 signaling pathway in targeted therapy for cancer. Cancer Treatment Reviews, 38(7), 904-910.

Haarmann, A., Nowak, E., Deiß, A., van der Pol, S., Monoranu, C.M., Kooij, G., Buttmann, M. (2015). Soluble VCAM-1 impairs human brain endothelial barrier integrity via integrin $\alpha$-4-transduced outside-in signalling. Acta Neuropathologica, 129(5), 639-652.

Hirohata, S. (1999). Human Th1 responses driven by IL-12 are associated with enhanced expression of CD40 ligand. Clinical and Experimental Immunology, 115(1), 78-85.

Holland, E.C. (2000). Glioblastoma multiforme: the terminator. Proceedings of the National Academy of Sciences of the United States of America, 97(12), 6242-6244. 
Huang, A.Y., Golumbek, P., Ahmadzadeh, M., Jaffee, E., Pardoll, D., Levitsky, H. (1994). Role of bone marrow-derived cells in presenting MHC class Irestricted tumor antigens. Science, 264(5161), 961-965.

Huang, S., Ullrich, S.E., Bar-Eli, M. (1999). Regulation of tumor growth and metastasis by interleukin-10: the melanoma experience. J Interferon Cytokine Research, 19(7), 697-703.

Huettner, C., Paulus, W., Roggendorf, W. (1995). Messenger RNA expression of the immunosuppressive cytokine IL-10 in human gliomas. The American Journal of Pathology, 146(2), 317-322.

Iglesia, N., Genevieve, K., Kah-Leong, L., Catherine, L.N., Jacqueline, F.B., David, A.F., Paul, S.M., David, N.L., Azad, B. (2008). Deregulation of a STAT3-Interleukin 8 Signaling Pathway Promotes Human Glioblastoma Cell Proliferation and Invasiveness. The Journal of Neuroscience, 28(23), 5870.

Ines, C., Ana, L.V., María, G.T., María, C.P., Alvaro, O., María, C.L., Catarina, O., Patricia, D., Alberto, O., Maria, D.T. (2015). Molecular and Genomic Alterations in Glioblastoma Multiforme. The American Journal of Pathology, 185(7), 1820-1833.

Jack, C.S., Nathalie, A., Joshua, M., Vivianne, M., Manon, B., Ellie, M., Aaron, S., Jack, P.A. (2005). TLR signaling tailors innate immune responses in human microglia and astrocytes. The Journal of Immunology, 175(7), 4320-4330.

Janson, K., Nedzi, L.A., David, O., Schorin, M., Walsh, J.W., Bhattacharjee, M., Biegel, J.A. (2006). Predisposition to atypical teratoid/rhabdoid tumor due to an inheritedINI1 mutation. Pediatric Blood and Cancer, 47(3), 279-284.

Kawakami, M., Kawakami K., Puri, R. (2003). Interleukin-4-Pseudomonas Exotoxin Chimeric Fusion Protein for Malignant Glioma Therapy. Journal of Neuro-Oncology, 65(1), 15-25.

Kazuya, S., Jan, V.D., Mark, Y.S., Sally, R.S., Richard, T.C., Ralph, A.T., Charles, C., Frederick, W.Q., Tetsuya, N., Dario, A.A. Vignali, P.C. Doherty, G.G., Paul, W.E., Ihle, J.N. (1996). Lack of IL-4-induced Th2 response and IgE class switching in mice with disrupted State6 gene. Nature, 380, 630-633.

Ke, Q., Qin, L., Thomas, P. E., Hong, S., Max, C. (2008). Nickel compounds induce phosphorylation of histone $\mathrm{H} 3$ at serine 10 by activating JNKMAPK pathway. Carcinogenesis, 29(6), 1276-1281.

Kleihues, P.C. (1997) In: Pathology and Genetics of Tumors of the Nervous System. Kleihues, P., Cavenee, W.K., editors. International Agency for Research on Cancer; Lyon, France.

Kore, R.A., Abraham, E.C. (2014). Inflammatory cytokines, interleukin-1 beta and tumor necrosis factor-alpha, upregulated in glioblastoma multiforme, raise the levels of CRYAB in exosomes secreted by U373 glioma cells. Biochemical and Biophysical Research Communications, 453(3), 326331 .

Lapointe, S., Perry, A., Butowski, N.A. (2018). Primary Brain Tumours in Adults. The Lancet, 392 (10145), 432-446.

Ledeboer, A., John, J.P.B., Anne, W., Saskia, V.J., Adrian, F.B., Josée, E.L., Fred, J.H.T., Anne-Marie, V.D. (2002). Expression and regulation of interleukin-10 and interleukin-10 receptor in rat astroglial and microglial cells. European Journal of Neuroscience, 16(7), 1175-1185.

Leonard, S.S., Bower, J.J., Shi, X. (2004). Metal-induced toxicity, carcinogenesis, mechanisms and cellular responses. Molecular and Cellular Biochemistry, 255(1-2), 3-10.

Lewis, C.E., Pollard, J.W. (2006). Distinct Role of Macrophages in Different Tumor Microenvironments. Cancer Research 66(2), 605-612.

Li, Z., Chen, L., Qin, Z. (2009). Paradoxical roles of IL-4 in tumor immunity. Cellular and Molecular Immunology, 6(6), 415-422.

Lichtor, T., Roberta, P.G., Katherine, T., Shannon, M., Elizabeth, M., Edward, P. C. (2002). Application of interleukin-2-secreting syngeneic/allogeneic fibroblasts in the treatment of primary and metastatic brain tumors. Cancer Gene Therapy, 9(5), 464-469.

Liu, Q., Gang, L., Ronghui, Li., Jie, S., Qiaowei, H., Lin, D., Cai, Z., Jian, Z. (2010). IL-6 promotion of glioblastoma cell invasion and angiogenesis in U251 and T98G cell lines. Journal of Neuro-Oncology, 100(2), 165-176.

Lobo-Silva, D., Guilhermina M. Carriche, A. Gil, C., Susana R., Margarida, S. (2016). Balancing the immune response in the brain: IL-10 and its regulation. Journal of Neuroinflammation, 13(1), 297.

Macmillan Cancer Support. Types of brain tumors. Available from http://www.macmillan.org.uk.
Martinez-Maza, O., Berek, J.S. (1991). Interleukin 6 and cancer treatment. In Vivo, 5(6), 583-588.

Meir, E.V., Sawamura, Y., Diserens, A.C., Hamou, M.F., Tribolet, N. (1990). Human Glioblastoma Cells Release Interleukin 6 in vivo and in vitro. Cancer Research, 50, 6683-6688.

Reilly, K.M. (2009). Brain tumor susceptibility: the role of genetic factors and uses of mouse models to unravel risk. Brain pathology (Zurich, Switzerland), 19(1), 121-131.

Romani, M., Pistillo, M.P., Banelli, B. (2018). Epigenetic Targeting of Glioblastoma. Frontiers in Oncology, 8, 448

Rutledge, W.C., Kong, J., Gao, J., Gutman, D.A., Cooper, L.A., Appin, C., Park, Y., Scarpace, L., Mikkelsen, T., Cohen, M.L., Aldape, K.D., McLendon, R.E., Lehman, N.L., Miller, C.R., Schniederjan, M.J., Brennan, C.W., Saltz, J. H., Moreno, C.S., Brat, D.J. (2013). Tumorinfiltrating lymphocytes in glioblastoma are associated with specific genomic alterations and related to transcriptional class. Clinical Cancer Research, 19(18), 4951-60.

Saleh, M., Davis, I.D., Wikis, A.F. (1997). The paracrine role of tumourderived mIL-4 on tumour-associated endothelium. International Journal of Cancer, 72(4), 664-672.

Segal, B.M., Deborah, D.G., Ethan, M.S. (2002). IL-10 -Producing CD4+ T cells Mediate Tumor Rejection. The journal of Immunology, 168, 1-4.

Seiichi, Y., Ryuichi, T., Nobuyuki, T. (1988). Immunological study of Interleukin-2 in Patients with Malignant Brain Tumors. Neurologia Medico-Chirurgica (Tokyo), 28, 631-634.

Shimamura, T., Hussain, S.R., Puri, R.K. (2006). The IL-4 and IL-13 pseudomonas exotoxins: new hope for brain tumor therapy." Neurosurgical Focus, 20(4), E11.

Tanabe, S., Yamashita, Y. (2018). The role of immune cells in brain development and neurodevelopmental diseases. International Immunology, 30(10), 437-444.

Tugues, S., Burkhard, S.H., Ohs, I., Vrohlings, M., Nussbaum, K., Vom Berg, J., Kulig, P., Becher, B. (2015). New insights into IL-12-mediated tumor suppression. Cell Death and Differentiation, 22(2), 237-246.

Voronov, E., Shouval, D.S., Krelin, Y., Cagnano, E., Benharroch, D., Iwakura, Y., Dinarello, C.A. Apte, R.N. (2003). IL-1 is required for tumor invasiveness and angiogenesis. Proceedings of National Academy of Sciences 100(5), 2645-2650

Vida, S., Richardson, L., Cardis, E., Krewski, D., McBride, M., Parent, M. E., Abrahamowicz, M., Leffondré, K., Siemiatycki, J. (2014). Brain tumours and cigarette smoking: analysis of the INTERPHONE Canada casecontrol study. Environmental Health, 13, 55.

Volpert, O.V., Fong, T., Koch, A.E., Peterson, J.D., Waltenbaugh, C., Tepper, R.I., Bouck, N.P. (1998). Inhibition of angiogenesis by interleukin 4. The Journal of experimental medicine, 188(6), 1039-1046.

Vom Berg, J., Vrohlings, M., Haller, S., Haimovici, A., Kulig, P., Sledzinska, A., Weller, M., Becher, B. (2013). Intratumoral IL-12 combined with CTLA-4 blockade elicits T cell-mediated glioma rejection. The Journal of Experimental Medicine, 210(13), 2803-2811.

Wainwright, D.A., Dey, M., Chang, A., Lesniak, M.S. (2013). Targeting Tregs in Malignant Brain Cancer: Overcoming IDO. Frontiers Immunology, 4, 116.

Wang, H., Lathia, J.D., Wu, Q., Wang, J., Li, Z., Heddleston, J.M., Rich, J.N. (2009). Targeting Interleukin 6 Signaling Suppresses Glioma Stem Cell Survival and Tumor Growth. Stem Cells (Dayton, Ohio), 27(10), 23932404.

Wang, L., Liu, Z., Balivada, S., Shrestha, T., Bossmann, S., Pyle, M., Pappan, L., Shi, J., Troyer, D. (2012). Interleukin-1 $\beta$ and transforming growth factor- $\beta$ cooperate to induce neurosphere formation and increase tumorigenicity of adherent LN-229 glioma cells. Stem Cell Research and Therapy, 3(1), 5 .

Watters, J.J., Schartner, J.M., Badie, B. (2005). Microglia function in brain tumors. Journal of Neuroscience Research, 81(3), 447-455.

Weiss, J.M., Subleski, J.J., Wigginton, J.M., Wiltrout, R.H. (2007). Immunotherapy of Cancer by IL-12-based Cytokine Combinations. Expert Opinion on Biological Therapy, 7(11), 1705-1721 (2007).

White, M. K., Gordon, J., Reiss, K., Del Valle, L., Croul, S., Giordano, A., Darbinyan, A., Khalili, K. (2005). Human polyomaviruses and brain tumors. Brain Research Reviews, 50(1), 69-85. 
Masood et al. / Journal of Life and Bio-sciences Research Vol. 01, No. 02, pp. 82 -88, (2020)

Yeung, Y. T., McDonald, K. L., Grewal, T., Munoz, L. (2013). Interleukins in glioblastoma pathophysiology: implications for therapy. British Journal of Pharmacology, 168(3), 591-606.

Zhang, J.M., An, J. (2007). Cytokines, Inflammation and Pain. International Anesthesiology Clinics, 45(2), 27-37.

Zurolo, E., Marjolein, G., Anand, I., Jasper, A., Erwin, A. van V., Jan, J.H., Jaap, C., Reijneveld, Jan,. Gorter, A., Eleonora A. (2012). Regulation of Kir4.1 expression in astrocytes and astrocytic tumors: a role for interleukin-1 $\beta$. Journal of Neuroinflammation, 9(1), 280. 